\title{
Pérez Barrero S, Castro Morales J. El suicidio infantojuvenil. Lima: Centro Editorial de la Universidad Peruana Cayetano Heredia; 2011. p. 133.
}

El tema del suicidio en niños y adolescentes, constituye un problema de salud pública nacional e internacional, siendo de interés no solo para los profesionales de la salud, sino también para el público general, por el impacto y la repercusión que ocasiona un suicidio dentro de la sociedad. En este contexto, el presente libro titulado El suicidio infantojuvenil resulta de gran interés y relevancia clínica y social. Sus autores son dos reconocidos psiquiatras de prestigio internacional: Sergio Pérez Barrero de Cuba y Jorge Castro Morales del Perú. El libro muestra una portada sugerente y una edición cuidadosa, contiene 133 páginas y 14 secciones, escritas con un estilo ágil y sencillo, con la finalidad de facilitar la lectura y la comprensión de los principales conceptos sobre el tema. La primera sección corresponde al prólogo, donde de manera acertada se establece que el público objetivo principal son los niños y adolescentes, los padres de familia, profesores y personal educativo. Además hay algunos capítulos dirigidos a los profesionales de la salud mental.

La segunda sección se titula Importancia del problema, la cual comienza con un marco teórico y social sobre el problema. Igualmente se presentan los resultados de los estudios epidemiológicos en salud mental realizados por el Instituto Nacional de Salud Mental "Honorio Delgado - Hideyo Noguchi" de 2002 a 2005, relacionados con indicadores suicidas en adolescentes, con el respectivo análisis crítico de los instrumentos y de los datos obtenidos. Hubiera sido interesante presentar resultados de estudios realizados en otros países, para contrastarlos con lo encontrado en el Perú y darle más fuerza a esta sección; por ejemplo, mostrar los resultados principales reportados en otro estudio de Evans y colaboradores (1). Sin embargo, se logra transmitir al lector la relevancia del problema. La tercera sección se titula La comunicación suicida, donde se muestra de manera didáctica y sistematizada, las cuatro variedades de comunicación suicida, tanto en niños como en adolescentes, las cuales son bien ilustradas con la presentación de viñetas de 8 casos clínicos. Esta información es de suma importancia, no solamente para los padres de familia y profesores, sino también para los profesionales de la salud mental. El conocer estos estilos de comunicación nos permite sospechar la presencia de riesgo suicida. No he encontrado ningún otro libro que presente este tema de la forma como se ha presentado en este libro. La cuarta, quinta y sexta secciones corresponden a factores de riesgo suicida en la niñez, factores de riesgo suicida en la adolescencia y factores de protección frente al comportamiento suicida, donde se describen de manera clara y organizada las condiciones clínicas, psicológicas, familiares y sociales que influyen aumentando o disminuyendo el riesgo suicida. Hubiera sido importante también describir los factores biológicos relacionados con el suicidio en niños y adolescentes. De la misma forma, citar algunas fuentes bibliográficas que sustenten la presencia de estos factores; por ejemplo mostrar los resultados de Evans y colaboradores (2). Sin embargo, estas secciones logran su cometido al mostrarnos con claridad el contexto sobre el cual se desarrolla el riesgo suicida.

La séptima sección se titula respuestas familiares ante las manifestaciones de la comunicación suicida, la que constituye una excelente síntesis de las reacciones que muestran los familiares cuando un miembro de su seno presenta deseos, pensamientos o intentos suicidas. Esto resulta fundamental, para corregir actitudes inadecuadas de la familia que pudieran aumentar el riesgo suicida. La octava sección corresponde a la Psicoterapia de la crisis suicida en el adolescente, donde se presenta de manera práctica y 
didáctica las intervenciones psicoterapéuticas básicas que debe utilizar el profesional de la salud mental cuando atiende estos casos. La novena sección ¿Qué debe hacer la familia? resulta de vital importancia. La mayoría de las veces la familia actúa inadecuadamente frente al problema o no sabe qué hacer. Aquí se muestra de forma clara y sencilla, cómo debe actuar la familia frente al problema. En la décima sección, Casos clínicos, se presentan 2 casos ilustrativos con su respectiva discusión clínica y psicoterapéutica que serán de utilidad práctica para los lectores. La presentación de casos clínicos es una herramienta útil para transmitir experiencias y orientar sobre las intervenciones adecuadas.

La décimo primera sección ha sido destinada a las preguntas que más frecuentemente realizan los adolescentes sobre el tema del suicidio. Su lectura permitirá a los adolescentes verse retratados y encontrar respuestas terapéuticas a muchas incertidumbres relacionadas con el suicidio. Se presenta una selección de 102 preguntas con sus respectivas respuestas. La décimo segunda sección se titula ¿Qué hacer cuando ha ocurrido el suicidio de un adolescente en la escuela?, acontecimiento que provoca un gran impacto en alumnos y profesores, sin saber estos últimos cómo manejar la situación. Se presentan 6 medidas breves y prácticas. La decimotercera sección, Criterios erróneos frente al suicidio, confronta 10 ideas erróneas con criterios científicos. Esta sección resulta de una utilidad práctica para padres de familia, profesores y profesionales de la salud mental, que puedan tener prejuicios o ideas erróneas sobre el suicidio. Buena parte de la bibliografía corresponde a libros y artículos escritos por uno de los autores (Sergio Pérez Barrero), aunque también hay varias fuentes que corresponden a la Organización Mundial de la Salud. Las fuentes citadas han constituido un cimiento sólido para la calidad del texto. Sin embargo, hubiera sido también interesante haber incluido otras fuentes bibliográficas que enriquecieran su contenido.

En síntesis, el libro logra el propósito de transmitir la experiencia clínica y humana sobre el suicidio infantojuvenil.

\section{REFERENCIAS BIBLIOGRÁFICAS}

1. Evans E, Hawton K, Rodham K, Deeks J. The prevalence of suicidal phenomena in adolescents: a systematic review of population-based studies. Suicide Life Threat Behav. 2005; 35(3): 239-50.

2. Evans E, Hawtonk, Rodham K. Factors associated with suicidal phenomena in adolescents: a systematic review of population-based studies. Clin Psychol Rev. 2004; 24(8): 957-79.

\section{Horacio Vargas Murga ${ }^{1}$}

1 Psiquiatra de niños y adolescentes. Profesor asociado y Jefe de la Sección Académica de Psiquiatría y Salud Mental de la Universidad Peruana Cayetano Heredia. Director de la Dirección Ejecutiva de Investigación, Docencia y Atención Especializada de Niños y Adolescentes del Instituto Nacional de Salud Mental "Honorio Delgado Hideyo Noguchi". Lima, Perú. 